\title{
Thermal Stability Enhancement of Cotton and Cotton Polyester Blend Fabrics by Hyperbranched Poly Urethane-Urea Treatment
}

\author{
K.M.Haggag ${ }^{1}$, A.I.Hashem ${ }^{2}$, F.N.EI Shall ${ }^{* 1}$ \\ ${ }^{1}$ Textile Research Division, National Research Centre and ${ }^{2}$ Faculty of Science, Ain \\ Shams University, Cairo, Egypt.
}

\begin{abstract}
D ESPITE the importance of cotton fabrics and its blends in our lives, the lack of their thermal stability is one of the most important points to be studied. The ability of hyperbranched poly urethane-urea (HBPU) to improve the thermal stability of cotton and cotton (CO) polyester (CO/PET) fabrics was investigated. Different concentrations of HBPU were used for treatment of both $\mathrm{CO}$ and $\mathrm{CO} / \mathrm{PET}$ fabrics. No significant effect on tensile strength properties was observed with $\mathrm{CO}$ fabrics, while tensile strength of treated $\mathrm{CO} / \mathrm{PET}$ fabrics was affected by treatment with different concentrations of HBPU. TGA analysis shows enhanced char residue values with both treated $\mathrm{CO}$ and $\mathrm{CO} / \mathrm{PET}$ fabrics. Polymer deposition on the surface of treated fabrics and structure changes were followed by SEM and FT-IR spectroscopy, respectively.
\end{abstract}

Keywords: Hyperbranched polymer, Thermal stability, Thermo-gravimetric analysis (TGA), Textile finishing.

\section{Introduction}

Textile Fabrics are one of the most important materials used in our daily life ever [1]. Improving all of their properties is a universal demand. Much of the research work has been done to produce fabrics possessing desired properties such as; resistance to microorganisms, resistance to ultraviolet light, flame resistance, improving their handle and comfort properties etc. [2-4]. Cotton fabrics are considered the top type in global consuming fabrics because of their required properties like; comfort, softness, biodegradation, warmness etc. The using of cotton blend fabrics, especially with synthetic fabric like polyester, is growing very fast because it combines the good properties of each component, such as the lower cost of polyester and comfort of cotton[3]. But the lack of thermal stability of cellulose fabrics and the ease of their fire combustion is the weak point for those fabrics [5], especially when producing high-performance and protective fabrics. Another important feature of blend fabrics is their being less ignitable with slow flame spread. But once ignition is started, synthetic fabrics melt with high rate of burning which double the risk that may lead to serious burning problems[2]. Therefore, the risk of combustion of blended fabrics is considered to be larger than that of natural or evensynthetic fabrics.
Moreover, there is a global trend to reduce the using of halogen compounds as fire retardant agents because of their environmental impact $[6,7]$. There is a general care for synthesis of formulations that enhances the thermal stability and therefore the flame retardancy with low environmental impact. Different lines have been carried out in the textile field, for example; phosphorus species, polyhedral ligomeric silsesquioxanes and silica particles, have been studied to reach this aim in the finishing stage of the textile stuffs $[3,7]$.

On the other hand, new classes of organic polymers called hyperbranched polymers (HBP), extremely branched macro-molecules with large number of reactive end-groups, have been recently studied [8-10]. These types of polymers possess superior properties from being more reactive such as compact shape, lower viscosity, better solubility, retain great numbers of reactive end functions groups [11]. Because of previously mentioned features, these polymers found large application in characteristic fields like nano-materials, biomedical applications, photochemical molecular devices, coating additives and textile finishing etc. $[12,13]$. However to the best of our knowledge, the effect of HBPU treatment finishing on the thermal properties of cotton fabric and blend cotton fabric has not been studied before. 
The aim of the present work is to investigate the ability of the prepared hyperbranched poly urethane-urea (HBPU) to enhance the thermal stability of cotton and cotton polyester blend fabrics. Thermal stability of fabrics is studied using thermo-gravimetric analysis (TGA) and differential thermo-gravimetric analysis (DTG) to test the impact of polymers on fabrics stability. Also, the effect of different concentrations of HBPU on tensile strength value of fabrics is examined. The change in fabrics surface morphology before and after the treatment with HBPU were investigated by scanning electron microscope (SEM).

\section{Experimental}

\section{Material}

$100 \%$ scoured bleached cotton (CO) fabric of $140 \mathrm{~g} / \mathrm{m}^{2}$ and $50 / 50$ cotton polyester blend $(\mathrm{CO} /$ PET) Knitted fabric of $170 \mathrm{~g} / \mathrm{m} 2$ are supplied by Weaving, Mehalla El - Kubra, Egypt. Synthesized Hyperbranched poly (urethane-urea). $\mathrm{N}, \mathrm{N}$-dimethyl formamide (DMF) from ACROS Chemical Co.

\section{Method}

Hyperbranched poly urethane-urea (HBPU) was synthesized by direct polymerization of isophoron diisocyanate and diethanol amine monomers according to procedure described [14, 15]. In brief, to a solution of $0.1 \mathrm{~mol}$ of diethanol amine in $100 \mathrm{~mL}$ of DMA, $0.1 \mathrm{~mol}$ of isophoron diisocyanet in $100 \mathrm{~mL}$ of DMA was added under vigorous stirring and nitrogen atmosphere. The mixture was kept at $80^{\circ} \mathrm{C}$ for $120 \mathrm{~min}$, then poured into diethyl ether solution. The precipitate was collected and dried under vacuum at $80{ }^{\circ} \mathrm{C}$ for 24 hr.

After the fabrics have been washed and dried, they were dipped in the DMF solution with varied $(1,3,5 \& 7 \mathrm{~g} / \mathrm{L})$ concentration of HPPU finishing bath for $15 \mathrm{~min}$, squeezed by a laboratory padder (Mathis HVF) with two dips and two nips to approximately wet pick up $100 \%$. The samples were dried and cured at a specified temperature $\left(160{ }^{\circ} \mathrm{C}\right)$ for $6 \mathrm{~min}$ in a laboratory curing oven (Wemer Mathis Co., automatic thermostatic oven, Switzerland). The fabric properties were measured after the treated fabrics were subjected to one washing cycle by tab water to remove any residue of solvent or unfixed HBPU particles followed by drying.
Analysis

Fabric performance evaluation

The treated samples tensile strength is evaluated by the ASTM standard Method D5035. Asano machine textile tensile strength tester was used. The tensile specimens were cut in rectangular shapes with dimensions of $20 \mathrm{~cm}$ in length and $5 \mathrm{~cm}$ in width. Three specimens for each treated fabric were tested in the warp direction. The results obtained were the average vales of three readings.

Weight add on were calculated according to equation (1):

$$
\text { Add }- \text { on }(\%)=\frac{W_{2}-W_{1}}{W_{1}} \times 100
$$

\section{Stiffness properties}

Stiffness of printed and unprinted samples was determined according to ASTM test method D 1388 - 96 using the cantilever apparatus (ASTM 1388 - 96, 2002).

\section{Handle properties}

The change in roughness values was measured for treated and untreated fabrics using a surface roughness measuring instrument SEL700 $\alpha$. The presented results are average of three readings.

Thermo-gravimetric analysis (TGA)

The thermo-gravimetric analyses (TGA) of the fabrics samples are studied using a differential scanning calorimeter analysis tool. The test was performed to study the structural changes of the treated fabrics with thermal treatment. A $10 \mathrm{mg}$ of sample was heated up to $700{ }^{\circ} \mathrm{C}$, with a heating rate of $10{ }^{\circ} \mathrm{C} \mathrm{min}{ }^{-1}$ in a nitrogen flow at a rate of $100 \mathrm{ml} \mathrm{min}^{-1}$ on SDTQ-600 (TA-USA) thermo balance instrument.

\section{FTIR spectroscopy analysis}

FT-IR spectra of the treated fabrics were recorded on JASCO FT-IR 6100 spectrometer (Tokyo, Japan). The transmission measurements are carried out within the range of $4000-400 \mathrm{~cm}^{-1}$.

Scanning electron microscope (SEM) analysis

SEM micrographs of samples were recorded on a Quanta FEG-250 microscope at a voltage of $10 \mathrm{kV}$. The samples were sputter-coated with gold before scanning to avoid charging.

\section{$\underline{\text { Results and Discussion }}$}

\section{Characterization of synthesized HBPU}

The IR spectrum of HBPU is given in Fig.1. The spectrum reveales the appearance of HBPU 
characteristic absorption broad band at $3382 \mathrm{~cm}^{-}$ ${ }^{1}$, which is corresponding to the overlapped $-\mathrm{OH}$ stretching and $-\mathrm{NH}$ stretching vibrations. The band at $2949 \mathrm{~cm}^{-1}$ is assigned to $\mathrm{C}-\mathrm{H}$ stretching. The two peaks around $1618 \mathrm{~cm}^{-1} \& 1581 \mathrm{~cm}^{-1}$ may be attributed to $\mathrm{C}=\mathrm{O}$ of urethano unit (NHCOO) and ureido unit (NHCONH), respectively. The bands at $1411 \mathrm{~cm}^{-1}, 1264 \mathrm{~cm}^{-1}, 1238 \mathrm{~cm}^{-1}$ and 1039 $\mathrm{cm}^{-1}$ are corresponding to $\mathrm{C}-\mathrm{H}$ bending, $\mathrm{O}-\mathrm{H}$ bending, $\mathrm{C}-\mathrm{N}$ bending and $\mathrm{C}-\mathrm{O}$ stretching of ester group, respectively. Moreover, the disappearance of absorption band in the range between $2100 \mathrm{~cm}^{-1}$ $-2270 \mathrm{~cm}^{-1}$, which is assigned to NCO isocyanate group, is an indication of complete consuming of isocyanate groups (from isophoro diisocyanate start) during the polymerization reaction.
The Mn (The number average molecular weight), Mw (the weight average molecular weight) and PDI polydisperesity index (the weight average molecular weight divided by number average molecular weight) of synthesized HBPU found to be $1.93311 \mathrm{e}^{4} \mathrm{~g} / \mathrm{mol}, 1.4319 \mathrm{e}^{4} \mathrm{~g} / \mathrm{mol}$ and $1.35 \mathrm{e}^{0}$, respectively using Gel Permeation Chromatography (GPC). The suggested structure of HBPU is given in Fig. 2 [16].

\section{Tensile strength performance of fabrics}

The tensile strength of untreated and treated cotton and cotton polyester blend fabrics with $(1,3$, $5 \& 7 \mathrm{~g} / \mathrm{L})$ of synthesized HBPU are listed in Tables $1 \& 2$ and Fig. $3 \& 4$, respectively. From these results It is evident that, the tensile strength of $\mathrm{CO}$ fabrics were not significantly affected by the treatment

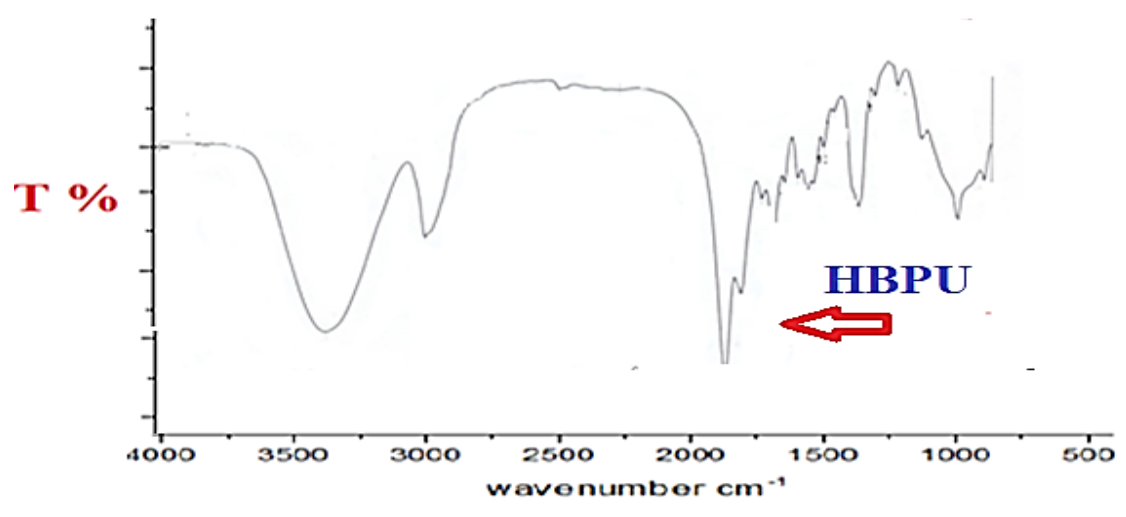

Fig. 1. FT-IR spectra of HBPU.

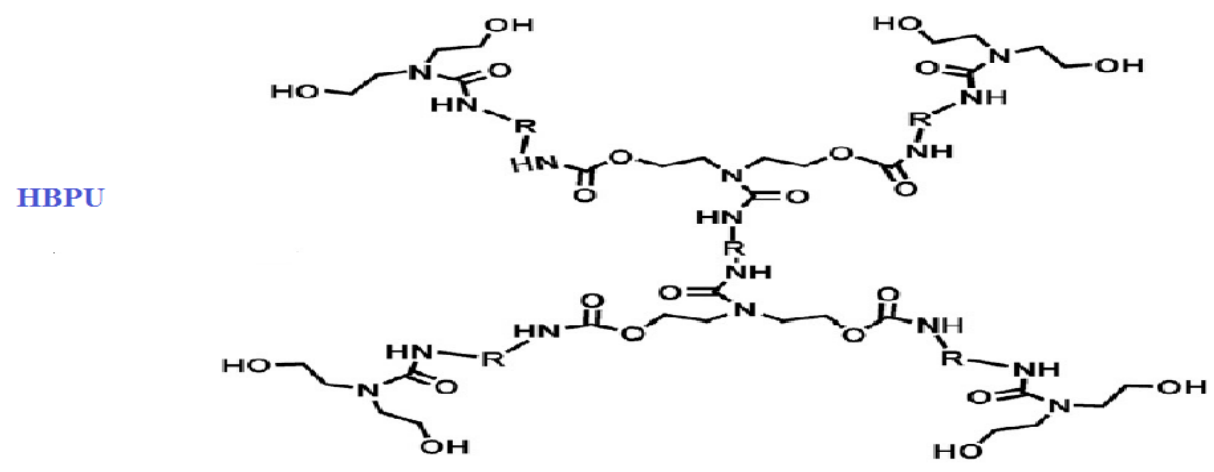

Fig. 2. HBPU structure.

with HBPU. However, when $\mathrm{CO}$ fabric was treated with $5 \mathrm{~g} / \mathrm{L}$ of HBPU, a slight improvement in tensile strength was observed.

In the case of the CO/PET fabrics, the situation is somewhat different. The tensile strength decreased by increasing the concentration of HBPU in treatment bath, which may be due to the negative impact of HBPU treatment on the polyester fraction in $\mathrm{CO} / \mathrm{PET}$ fabrics.
From Tables 1 and 2, It is noticed that there is an increase of the weight picked up by $\mathrm{CO}$ and $\mathrm{CO} / \mathrm{PET}$ fabrics with increasing the concentration of HBPU in the treating bath. This could be related to the increase of HBPU deposits inside fabrics as the polymer concentration increases in treatment solution bath. Therefore, we can conclud that, the affinity of $\mathrm{CO}$ fabrics to retain polymer deposits inside them are less than $\mathrm{CO} /$ PET fabrics. 
TABLE 1. Tensile strength, elongation and weight add on of $\mathrm{CO}$ fabrics treated with varied HBPU concentrations.

\begin{tabular}{cccc}
\hline HBPU & Tensile strength & Elongation & Add-on \\
$(\mathbf{g} / \mathbf{L})$ & $(\mathbf{M P a})$ & $\mathbf{( \% )}$ & $\mathbf{( \% )}$ \\
\hline 0 & $64 \pm 5.98$ & $24 \pm 1.05$ & -- \\
1 & $62 \pm 2.52$ & $22 \pm 1.68$ & 2.38 \\
3 & $64 \pm 7.00$ & $22 \pm 3.04$ & 4.27 \\
5 & $66 \pm 4.25$ & $19 \pm 0.78$ & 5.46 \\
7 & $64 \pm 5.03$ & $22 \pm 2.15$ & 7.84 \\
\hline
\end{tabular}

TABLE 2. Tensile strength, elongation and weight add on values of CO/PET fabrics treated with varied HBPU concentrations.

\begin{tabular}{cccc}
\hline $\begin{array}{c}\text { HBPU } \\
(\mathbf{g} / \mathbf{L})\end{array}$ & $\begin{array}{c}\text { Tensile strength } \\
(\mathbf{M P a})\end{array}$ & $\begin{array}{c}\text { Elongation } \\
\mathbf{( \% )}\end{array}$ & $\begin{array}{c}\text { Add-on } \\
\mathbf{( \% )}\end{array}$ \\
\hline 0 & $140 \pm 10.52$ & $22 \pm 1.36$ & - \\
1 & $140 \pm 9.53$ & $26 \pm 1.93$ & 1.95 \\
3 & $130 \pm 7.26$ & $27 \pm 2.50$ & 2.82 \\
5 & $100 \pm 4.68$ & $18 \pm 1.25$ & 7.53 \\
7 & $100 \pm 7.41$ & $22 \pm 0.96$ & 10.14 \\
\hline
\end{tabular}

Fig. 3. Effect of HBPU treatment at varied concentration on the tensile strength of treated CO fabric.

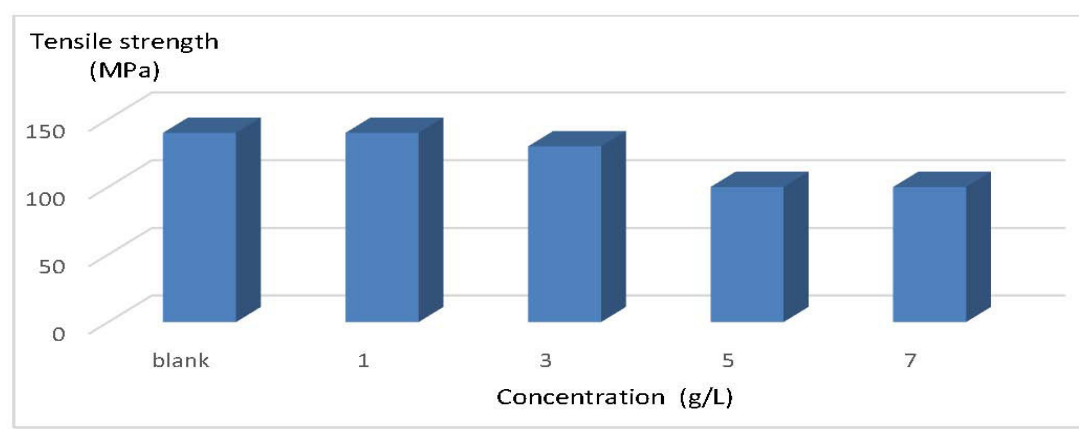

Fig. 4. Effect of HBPU at varied concentration on the tensile strength values of treated CO/PET fabrics.

Egypt. J. Chem. 60, No.5 (2017) 


\section{Stiffness performance of fabrics}

Table 3 shows the stiffness values of treated and untreated $\mathrm{CO}$ and $\mathrm{CO} / \mathrm{PET}$ fabrics. From the stiffness values corresponding to $\mathrm{CO}$ fabrics It was observed that, both 3 and $5 \mathrm{~g} / \mathrm{L} \mathrm{HBPU}$ treated fabrics show improved stiffness values and have good handling when compared to 1 and $7 \mathrm{~g} / \mathrm{L}$ HBPU treatment. However, in the case of CO/PET fabrics both of 5 and $7 \mathrm{~g} / \mathrm{L}$ HBPU treated fabrics possess superior stiffness\& handling character compered to neat $\mathrm{CO} / \mathrm{PET}$.

\section{Handling properties of fabrics}

From Table 4 it is clear that, all the roughness values of treated $\mathrm{CO} / \mathrm{PET}$ fabrics reflect an improvement when compared with neat CO/PET at all treatment concentration. However, in case of $\mathrm{CO}$ fabrics the roughness characters are slightly changed by treatment with HBPU.

\section{Thermal behavior of fabrics}

TGA and DTG analyses were carried out to investigate the thermal decomposition behavior of treated and untreated fabrics (Fig.5\&6).

TABLE 3. Stiffness properties of treated and untreated $\mathrm{CO}$ and $\mathrm{CO} / \mathrm{PET}$ fabrics with varied HBPU concentrations.

\begin{tabular}{|c|c|c|}
\hline (mg.cm) & $\mathrm{CO}$ & CO/PET \\
\hline Blank & 1174.8 & 1673.2 \\
\hline 1 & 1317.2 & 1886.8 \\
\hline 3 & 569.6 & 2670.8 \\
\hline 5 & 1068.0 & 1103.0 \\
\hline 7 & 1673.2 & 996.0 \\
\hline
\end{tabular}

TABLE 4. Roughness properties of treated and untreated $\mathrm{CO}$ and $\mathrm{CO} / \mathrm{PET}$ fabrics with varied HBPU concentrations.

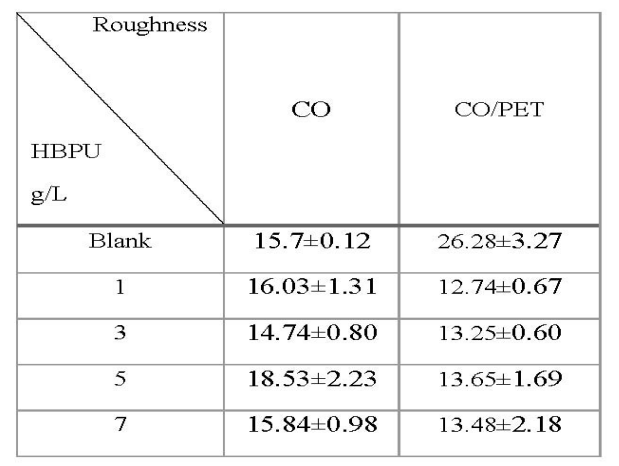

When cotton cellulose is exposed to thermal decomposition the pyrolysis process takes place in two steps. The first step occurred at lower temperature is corresponding to adsorbed water evaporation and char formation. The second step takes place at a higher temperature and is believed to be responsible for cellulose polymer depolymerization. The depolymerization of cellulose results in the formation of levoglucosan which in consequence leads to the creation of highly flammable volatile products [3, 17-20].

On the other hand, the thermal degradation of polyester, takes place through random scission of the ester bonds along polymer chains followed by pyrolysis of small esters formed [21].

The thermal stability of treated and untreated $\mathrm{CO}$ and CO/PET fabrics are studied by TGA analytical tool, the data are illustrarated by Fig. 5 and 6, respectively. The mathematical explanations of TGA \& DTG profiles are listed in Tables 5 and 6 .

Blank $\mathrm{CO}$ fabric and treated $\mathrm{CO}$ fabric with $1 \mathrm{~g} / \mathrm{L}$ HBPU demonstrate comparable decomposition performance. From DTG profiles, one degradation step with maximum degradation temperature $\left(T_{\text {max }}\right)$ in range between $(303-383){ }^{\circ} \mathrm{C}$ and (299-392) ${ }^{\circ} \mathrm{C}$ were observed, respectively. The appearance of one degradation step during the thermal decomposition of blank and $1 \mathrm{~g} / \mathrm{L}$ treated $\mathrm{CO}$ fabrics at the temperature ranges clarified above, demonstrate the degradation of the samples by the formation of char from decomposition of the glycosyl units at lower degradation temperatures. As HPBU concentration increases ( $\gg 1 \mathrm{~g} / \mathrm{L}$ ) in the finishing bath, the treated $\mathrm{CO}$ fabrics exhibit two stages of decomposition with two $T_{\text {max }}$ of degradation. (254\&297);(316\&394) ${ }^{\circ} \mathrm{C}$, (214\&284);(304\&382) ${ }^{\circ} \mathrm{C}$ and (241\&282);(306 $\& 380)^{\circ} \mathrm{C}$. These repesent the temperature ranges corresponding to the two degradation stages of $\mathrm{CO}$ fabrics treated with 3,5 and $7 \mathrm{~g} / \mathrm{L}$ of HBPU, respectively. From the above results it is clear that, the thermal stability of treated CO fabrics is affected by HBPU treatment. The values of $T_{o 2}$ and $T_{\max }$ of treated fabrics decreases as the concentration of HBPU increases during treatment process.

The value of char residue at different decomposition temperatures is a very distinctive signal wich distinguishes the thermal stability of the fabrics. The higher its residual value is, the greater the thermal stability of certain fabrics 

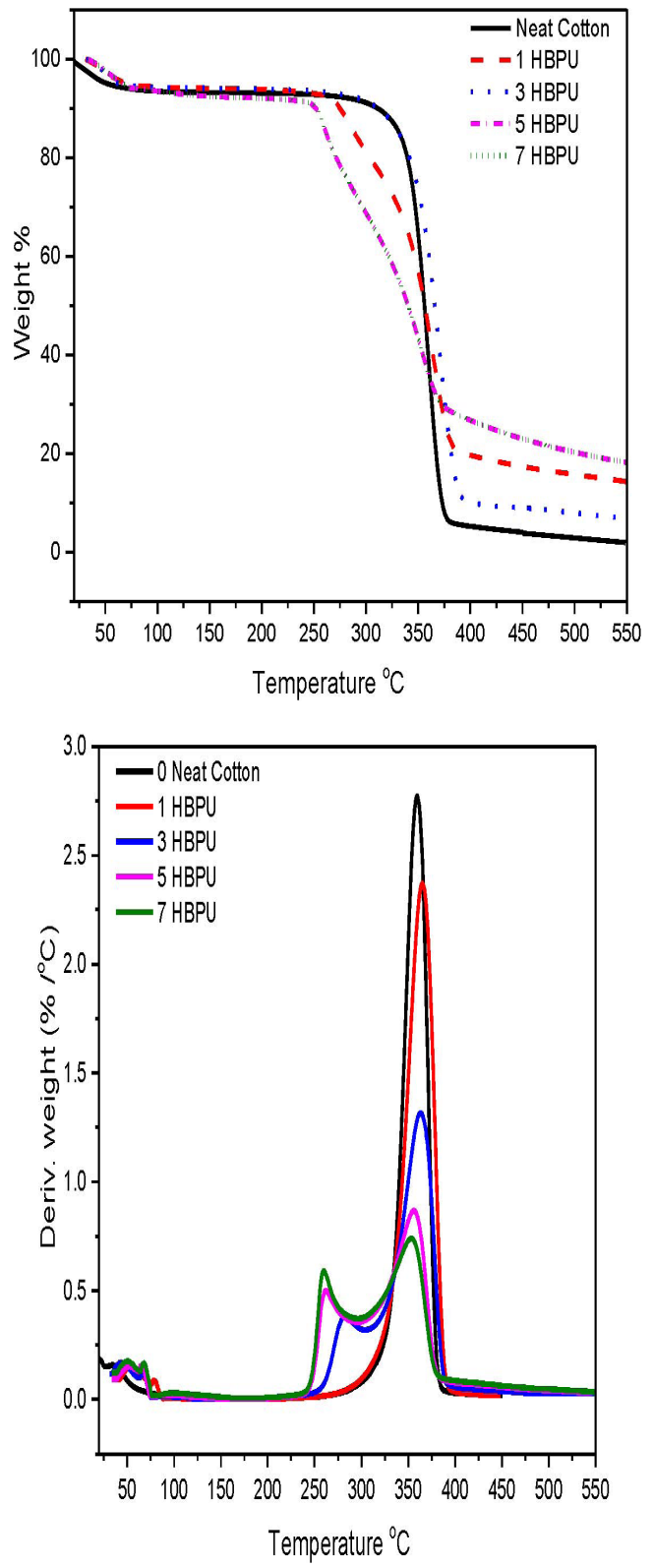

Fig. 5. TGA \& DTG curves of blank and treated CO fabrics at varied concentrations $(\mathrm{g} / \mathrm{L})$ of HBPU.

will be found. The results showed that, the residual char wt $\%$ of blank $\mathrm{CO}$ fabric at $T_{\max l}$ and $500^{\circ} \mathrm{C}$ are about 42.78 and $2.72 \%$, respectively. A very distinctive char residue values were obtained through thermal degradation of treated of $\mathrm{CO}$ fabric with $5 \mathrm{~g} / \mathrm{L}$ HPBU at different decomposition temperatures, the values were $89.08,42.98 \& 21.85 \%$ from the total weight of treated fabrics at $T_{\max 1}, T_{\max 2}$ and $500^{\circ} \mathrm{C}$, respectively. The higher char residue values after treatment with HBPU could be attributed to the
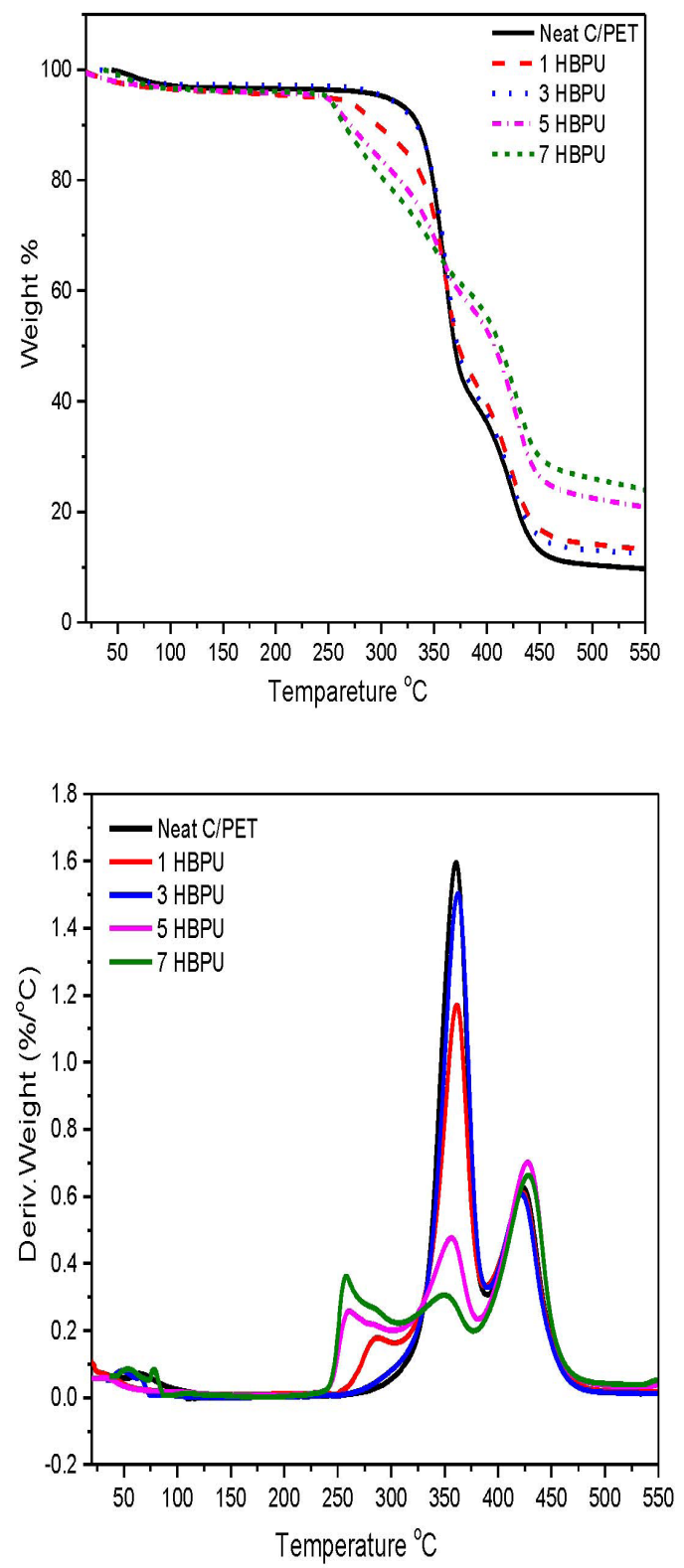

Fig. 6. TGA \& DTG curves of blank and treated CO polyester blend fabrics at varied concentrations (g/L) of HBPU.

increasing ability of fabrics towards the creation of less volatiles and nonflammable products at lower temperature range, which in turn delay the thermal decomposition and increase their thermal stability. From the above results, it could be concluded that the treatment of CO fabrics with HBPU polymer enhances their thermal stability and the recommended HBPU concentration for treatment of CO fabric is $5 \mathrm{~g} / \mathrm{L} \mathrm{HBPU}$ at which the remaining char residual value is about 10 times greater than the char value of blank $\mathrm{CO}$ fabric at 
$500{ }^{\circ} \mathrm{C}$.

In case of CO/PET fabrics, the following observations were detected; all samples showed two independent stages of thermal decomposition, the first stage (at lower temperature) is due to the CO fiber degradation while the later stage (at higher temperature) is due to the decomposition of polyester fiber $[1,22]$. Also, $T_{\max }$ and $\mathrm{T}_{\mathrm{ol}}$ values decrease as HBPU concentration increases during treatment process. Highest drop in $T_{\max l}$ is observed with CO/PET fabrics treated with $7 \mathrm{~g} / \mathrm{L}$ HBPU. While the values of $T_{\max 2}$ are almost unchanged with the change of polymer concentrations in the finishing bath.

TABLE 5. Thermo-gravimetric analytical data of untreated and treated $\mathrm{CO}$ fabrics at varied HBPU concentrations.

\begin{tabular}{cccccccc}
\hline $\begin{array}{c}\text { HBPU } \\
\mathbf{g} / \mathbf{L}\end{array}$ & $\begin{array}{c}\mathbf{T}_{\mathbf{0 1}} \\
{ }^{\circ} \mathbf{C}\end{array}$ & $\begin{array}{c}\mathbf{T}_{\max 1} \\
{ }^{\circ} \mathbf{C}\end{array}$ & $\begin{array}{c}\mathbf{C R}_{\max 1} \\
\mathbf{w t} \%\end{array}$ & $\begin{array}{c}\mathbf{T}_{\mathbf{0 2}} \\
{ }^{\circ} \mathbf{C}\end{array}$ & $\begin{array}{c}\mathbf{T}_{\max 2} \\
{ }^{\circ} \mathbf{C}\end{array}$ & $\begin{array}{c}\mathbf{C R}_{\max 2} \\
\mathbf{w t \%}\end{array}$ & $\begin{array}{c}\mathbf{C R}_{\mathbf{5 0 0}} \mathbf{C} \\
\mathbf{w t} \mathbf{o}\end{array}$ \\
\hline Blank & 342 & 358 & 42.78 & -- & -- & -- & 2.721 \\
1 & 302 & 360 & 48.42 & -- & -- & -- & 3.311 \\
3 & 257 & 282 & 87.54 & 317 & 364 & 39.68 & 15.571 \\
5 & 239 & 260 & 89.08 & 308 & 354 & 42.98 & 21.85 \\
7 & 243 & 258 & 86.87 & 303 & 353 & 39.81 & 20.27 \\
\hline
\end{tabular}

TABLE 6. Thermo-gravimetric analytical data of untreated and treated CO polyester blend fabrics at varied HBPU concentration.

\begin{tabular}{cccccccc}
$\begin{array}{c}\text { HBPU } \\
\mathbf{g} / \mathbf{L}\end{array}$ & $\begin{array}{c}\mathbf{T}_{\mathbf{o 1}} \\
{ }^{\circ} \mathbf{C}\end{array}$ & $\begin{array}{c}\mathbf{T}_{\max 1} \\
{ }^{\circ} \mathbf{C}\end{array}$ & $\begin{array}{c}\mathbf{C R}_{\max 1} \\
\mathbf{w t \%}\end{array}$ & $\begin{array}{c}\mathbf{T}_{\mathbf{0}} \\
{ }^{\circ} \mathbf{C}\end{array}$ & $\begin{array}{c}\mathbf{T}_{\text {max } 2} \\
{ }^{\circ} \mathbf{C}\end{array}$ & $\begin{array}{c}\mathbf{C R}_{\max 2} \\
\mathbf{w t \%}\end{array}$ & $\begin{array}{c}\mathbf{C R}_{\mathbf{5 0 0}}{ }^{\circ} \mathbf{C} \\
\mathbf{w t}_{\mathbf{0}}\end{array}$ \\
\hline Blank & 325 & 361 & 62.11 & 391 & 424 & 24.91 & 10.14 \\
1 & 321 & 362 & 60.85 & 393 & 423 & 27.24 & 14.12 \\
3 & 316 & 360 & 69.28 & 395 & 422 & 22.52 & 13.06 \\
5 & 312 & 355 & 66.66 & 387 & 426 & 37.68 & 22.53
\end{tabular}

Furthermore, the char residue value increases as polymer concentration increases during the treatment of $\mathrm{CO} / \mathrm{PET}$ fabrics. The highest char value was observed at $7 \mathrm{~g} / \mathrm{L}$ of HBPU treatment. The highest thermal stability detected with $\mathrm{CO} /$ PET fabrics were observed at $7 \mathrm{~g} / \mathrm{L}$ of HBPU, whereas the $T_{\text {max } /}$ value drop from $361^{\circ} \mathrm{C}$ to $349^{\circ} \mathrm{C}$ and the $\mathrm{CR}_{500^{\circ} \mathrm{C}}$ values increases from $10.14 \%$ to $25.97 \%$ at $500^{\circ} \mathrm{C}$. Thus it can be said that, the treatment of CO/PET fabrics with synthesized HBPU increases their thermal stability and char residue values when the fabric is subjected to higher temperature atmosphere.

From the above TGA and DTA results of CO and $\mathrm{CO} / \mathrm{PET}$ fabrics, It could be concluded that, the treatment of these fabrics with synthesized HBPU improves their thermal stability. Furthermore, the thermal stability enhancements in the case of $\mathrm{CO}$ fabrics were higher than that in the case of $\mathrm{CO} / \mathrm{PET}$ fabrics. This result is in agreement with the results obtained earlier for tensile strength measurements. However it appears that the polyester fibers do not respond well to HBPU treatment as $\mathrm{CO}$ fiber portion.

\section{FT-IR analysis}

The effect of treatment of $\mathrm{CO}$ and $\mathrm{CO} / \mathrm{PET}$ fabrics with 5 and $7 \mathrm{~g} / \mathrm{L} \mathrm{HBPU}$ on the chemical composition of $\mathrm{CO}$ and $\mathrm{CO} / \mathrm{PET}$ fabrics were studied by FT-IR spectroscopy. In general, it is clear that, HBPU treatment has a significant effect on the structure of both $\mathrm{CO}$ and $\mathrm{CO} / \mathrm{PET}$ fabrics. From IR spectra it was noticed that, all the treated fabrics ( $\mathrm{CO}$ and $\mathrm{CO} / \mathrm{PET})$ exhibited a change in peaks position and intensity (Fig. $7 \& 8$ ).

All the Peaks of neat $\mathrm{CO}$ and CO/PET appeared after the treatment with HBPU. The intensity and shapes of FTIR peaks after treatment changed considerably. HBPU peaks are clearly overlapped with the absorption bands of $\mathrm{CO}$ and $\mathrm{CO} / \mathrm{PET}$ fabrics. 
The broad band in the range 3750 to 3000 $\mathrm{cm}^{-1}$ is corresponding to inter and intra hydrogen bonding stretching vibration of $-\mathrm{OH}$ from cotton cellulose. The peaks appeared at $2920 \mathrm{~cm}^{-1}, 1650$ $\mathrm{cm}^{-1}$ and $1440 \mathrm{~cm}^{-1}$ are corresponding to $\mathrm{CH}$ stretching, $-\mathrm{OH}$ and $-\mathrm{CH}_{2}$ bending vibrations, respectively.

In case of $\mathrm{CO}$ fabrics, the peak attributed to str-OH located at $3427 \mathrm{~cm}^{-1}$ within neat $\mathrm{CO}$ fabric was shifted to $3425 \mathrm{~cm}^{-1}$ and $3421 \mathrm{~cm}^{-1}$ (lower frequency ) with samples treated with 5 and $7 \mathrm{~g} / \mathrm{L}$ HBPU respectively. The $\mathrm{CO}$ cellulose $\mathrm{C}-\mathrm{H}$ peak was also shifted to a lower wavenumber from $2911 \mathrm{~cm}^{-1}$ (neat CO) to $2901 \mathrm{~cm}^{-1}(5 \mathrm{~g} / \mathrm{L} \mathrm{HBPU}$ treated CO) and $2899 \mathrm{~cm}^{-1}(7 \mathrm{~g} / \mathrm{L}$ HBPU treated $\mathrm{CO}$ ). This shift may be attributed to the possible HBPU influence on inter and intra hydrogen bonding of cellulose $\mathrm{OH}$ groups and formation of new bonds.

Conversely, in case in CO/PET fabrics, the shifting in position of str-OH and str-C-H bands to lower frequency from neat to treated $\mathrm{CO} / \mathrm{PET}$ fabrics were not observed. However, a significant shift in position of str-C-O from $1090 \mathrm{~cm}^{-1}$ to and $1082 \mathrm{~cm}^{-1}$ of neat and $7 \mathrm{~g} / \mathrm{L}$ treated CO/PET, respectively occured One possible reason may be the inert chemical structure of polyester fibre in CO/PET fabric which may restrict the hydrogen bonding formation ability between CO/PET \& HBPU.

Moreover, all bands intensities in case of treated $\mathrm{CO}$ fabrics showed increase in intensity as compared with neat $\mathrm{CO}$, while reverse situation occurred with treated C/BET fabrics (the treated fabrics show a decrease in bands intensity when compared with neat CO/PET fabric). In general, the reduction of the bands absorption intensities means that a physical change has been occurred, while the increase in the band intensities means a change in the morphology and chemical composition of that band [23].

From all the above results, it seems that, $\mathrm{CO}$ fabrics showed a different response from CO/PET fabrics when treated with HBPU polymer.

\section{Scanning electron microscopy}

Figures 9 and 10 illustrate the surfaces morphology changes of fabrics respectively before and after HBPU treatment as investigated by SEM analysis. The $8 \mathrm{~A}$ and $9 \mathrm{~A}$ images represent SEM micrographs of surface of untreated $\mathrm{CO}$ and $\mathrm{CO} / \mathrm{PET}$ fabrics respectively, while $8 \mathrm{~B} \& 9 \mathrm{~B}$ images represent SEM micrographs of treated $\mathrm{CO}$ and $\mathrm{CO} / \mathrm{PET}$ fabrics with 5 and $7 \mathrm{~g} / \mathrm{L} \mathrm{HBPU}$, respectively. It is clear that, were formed polymer coating deposits on the surface of fabrics treated with HBPU $(5 \& 7 \mathrm{~g} / \mathrm{L})$, which is in contrast to the clean, smooth and clear surfaces of untreated fabrics. Although there are polymer coating deposits on the surface of treated fabrics, these deposits are not affected on fabrics fine structures and still appeared retaining their properties.

\section{Conclusion}

Enhancements in tensile strength properties were achieved by treating $\mathrm{CO}$ fabrics with $5 \mathrm{~g} / \mathrm{L}$ HBPU polymer, while CO/PET fabrics showed a reduction in tensile strength properties upon HBPU treatment. Also, the treated samples showed good handling. The thermal stability enhancement in the case of $\mathrm{CO}$ fabrics was higher than CO/PET fabrics. From TGA \& DTG results, both of treated $\mathrm{CO}$ and $\mathrm{CO} / \mathrm{PET}$ fabrics with $5 \mathrm{~g} / \mathrm{L}$ and $7 \mathrm{~g} / \mathrm{L}$ of HBPU, respectively, have improved thermal stability and may be utilized in high temperatures fabrics application. The type of interaction exists between HBPU and fabric (CO and CO/PET) after treatment were investigated by the FT-IR analysis. The peaks intensity of $\mathrm{CO}$ fabrics were enhanced after HBPU treatment, while CO/PET peaks intensity followed a different pathway. Also FT-IR spectral data revealed that, the interaction between $\mathrm{CO}$ fabrics and HBPU occurred by a different mechanism from $\mathrm{CO} / \mathrm{PET}$ fabrics.

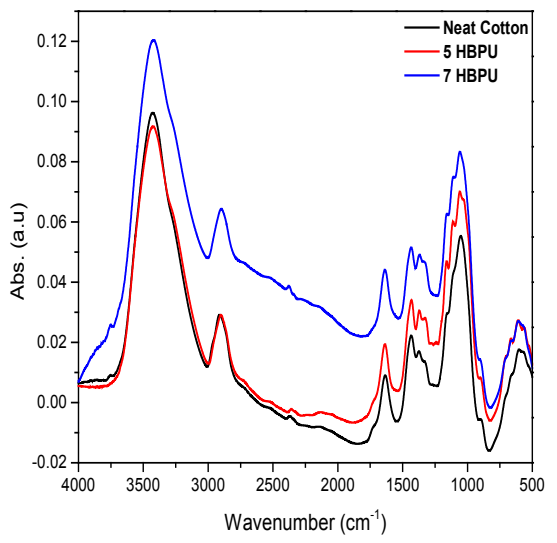

Fig .7. FT- IR spectra of $\mathrm{CO}$ fabrics before and after treatment with 7 and $5 \mathrm{~g} / \mathrm{L}$ HBPU. 


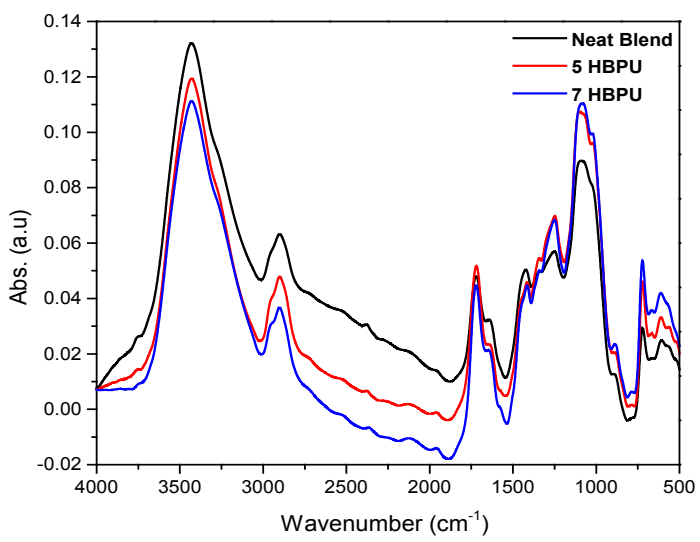

Fig. 8. FT- IR spectra of CO/PET fabrics before and after treatment with 7 and $5 \mathrm{~g} / \mathrm{L}$ HBPU.
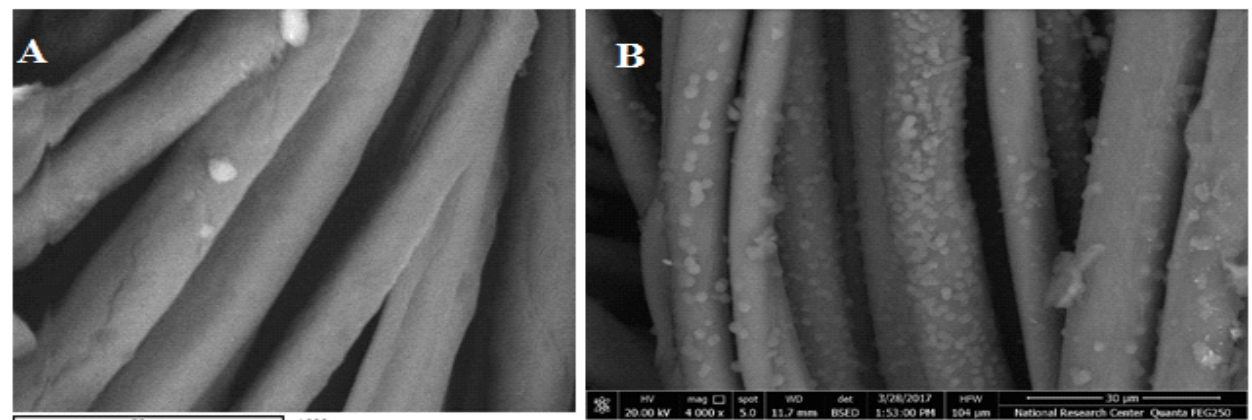

Fig 9. SEM micrographs of untreated (A) and treated CO fabric at $5 \mathrm{~g} / \mathrm{L} \mathrm{HBPU}$ (B).
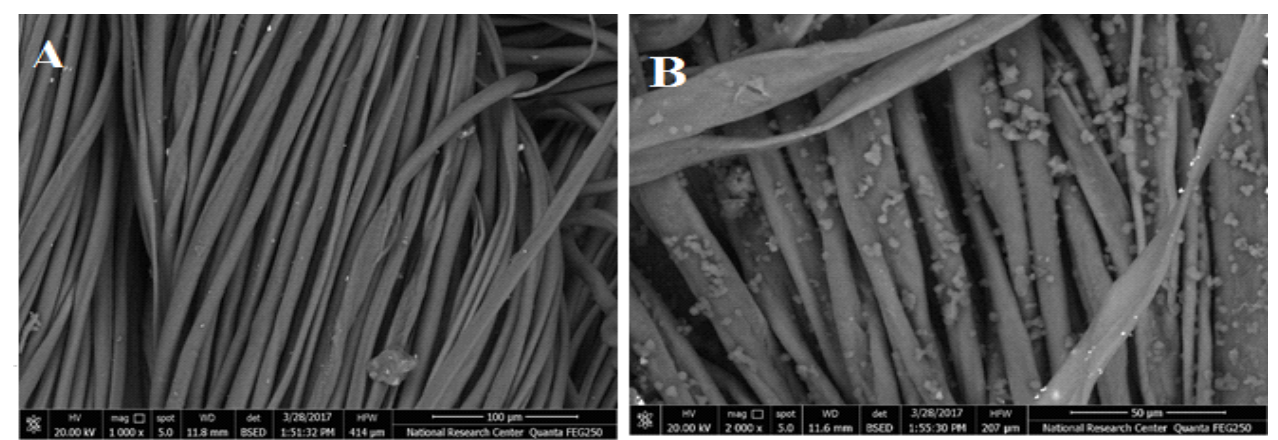

Fig. 10. SEM micrographs of untreated (A) and treated CO/PET fabrics at $7 \mathrm{~g} / \mathrm{L}$ HBPU (B).

\section{References}

1. Alongi, J., Ciobanu, M. and Malucelli, G., Solgel treatments for enhancing flame retardancy and thermal stability of $\mathrm{CO}$ fabrics: optimisation of the process and evaluation of the durability. Cellulose, 18, 167 (2010).

2. El-Hady, M.M., Farouk, A. and Sharaf, S., Flame retardancy and UV protection of $\mathrm{CO}$ based fabrics using nano $\mathrm{ZnO}$ and polycarboxylic acids. Carbohydr Polym, 92, 400 (2013).
3. Alongi, J., Ciobanu, M., Tata, J., Carosio, F., and Malucelli, G., Thermal stability and flame retardancy of polyester, $\mathrm{CO}$, and relative blend textile fabrics subjected to sol-gel treatments. Journal of Applied Polymer Science, 119, 1961 (2011).

4. Rosace, G., Guido, E., Colleoni C. and Barigozzi, G., Influence of textile structure and silica based finishing on thermal insulation properties of co fabrics. International Journal of Polymer Science,2016, 10 (2016)

Egypt. J. Chem. 60, No.5 (2017) 
5. Zhang, Q.H., Wei, Z., Guo-Qiang, C. and TieLing,. X., Combustion properties of $\mathrm{CO}$ fabric treated by boron doped silica sol. Thermal Science, 19, 1345 (2015).

6. Alongi, J., Ciobanu, M. and Malucelli, G., Thermal stability, flame retardancy and mechanical properties of $\mathrm{CO}$ fabrics treated with inorganic coatings synthesized through sol-gel processes. Carbohydrate Polymers, 87, 2093 (2012).

7. El-Shafei, A., ElShemy, M. and Abou-Okeil, A., Eco-friendly finishing agent for $\mathrm{CO}$ fabrics to improve flame retardant and antibacterial properties. Carbohydr Polym, 118, 83 (2015).

8. Yates, C. R. and Hayes, W., Synthesis and applications of hyperbranched polymers. European Polymer Journal, 40, 1257 (2004).

9. Jena, K.K., Chattopadhyay, D.K. and Raju K.V.S.N., Synthesis and characterization of hyperbranched polyurethane-urea coatings. European Polymer Journal, 43, 1825 (2007).

10. Bao, F. and Shi, W., Synthesis and properties of hyperbranched polyurethane acrylate used for UV curing coatings. Progress in Organic Coatings, 68, 334 (2010).

11. Zheng, Y., Li, S., Weng, Z. and Gao, C., Hyperbranched polymers: advances from synthesis to applications. Chemical Society Reviews, 44, 4091 (2015).

12. Mishra, R. S., Mishra, A. K. and Raju, K. V. S. N., Synthesis and property sudy of UV-curable hyperbranched polyurethane acrylate/ $\mathrm{ZnO}$ hybrid coatings. European Polymer Journal, 45, 960 (2009).

13. Ren, L.F., Geng, J., Chen, T., Guo, P. and Qiang, T., Synthesis and application of hyperbranched poly (urethane-urea) finishing agent with amino groups. Journal of Applied Polymer Science, 133,1 (2016).

14. Gao, C. and Yan, D., "A2+ CB n" Approach to Hyperbranched Polymers with Alternating Ureido and Urethano Units. Macromolecules, 36, 613 (2003).
15. FREY, H., Synthesis and characterization of hyperbranched poly (urea-urethane) s. $P h D$ Thesis. Technische Universität Dresden.(2004).

16. Fenfen, B. and Wenfang, S., Synthesis and properties of hyperbranched polyurethane acrylate used for UV curing coatings, Progress in Organic Coatings, 68, 334 (2010).

17. Alongi, J., Ciobanu, M., and Malucelli, G., Novel flame retardant finishing systems for $\mathrm{CO}$ fabrics based on phosphorus-containing compounds and silica derived from sol-gel processes. Carbohydrate Polymers, 85, 599 (2011).

18. Alongi, J., Ciobanu, M. and G. Malucelli, Sol-gel treatments on $\mathrm{CO}$ fabrics for improving thermal and flame stability: Effect of the structure of the alkoxysilane precursor. Carbohydrate Polymers, 87, 627 (2012).

19. Xu, L., Wang, W. and Yu, D., Durable flame retardant finishing of $\mathrm{CO}$ fabrics with halogen-free organophosphonate by UV photoinitiated thiolene click chemistry. Carbohydrate Polymers, 127, 275 (2017.).

20. Farouk, A. and Sharaf, S., Sol-gel hybrid nanomaterials based on $\mathrm{TiO} 2 / \mathrm{SiO} 2$ as multifunctional finishing for $\mathrm{CO}$ fabric. Egypt. $J$. Chem, 59, 407 (2016)

21. Braun, E. and Levin, B.C., Polyesters: a review of the literature on products of combustion and toxicity. Fire and Materials, 10, 107 (1986).

22. Carosio, F., Di Blasio, A., Cuttica, F., Alongi, J., and Malucelli, G., Flame retardancy of polyester and polyester-CO blends treated with caseins. Industrial \& Engineering Chemistry Research, 53, 3917 (2014).

23. Ozsagiroglu, E., Iyisan, B. and Guvenilir, Y.A., Biodegradation and characterization studies of different kinds of polyurethanes with several enzyme solutions. Polish Journal of Environmental Studies, 21, 1777 (2012).

(Received 18/6/2017; accepted 30/7/2017) 


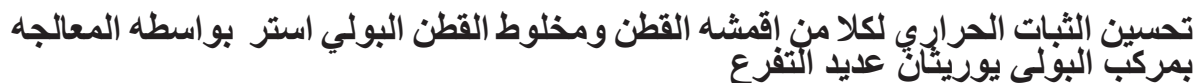

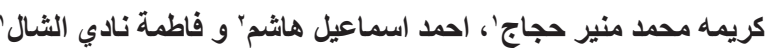

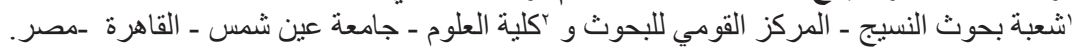

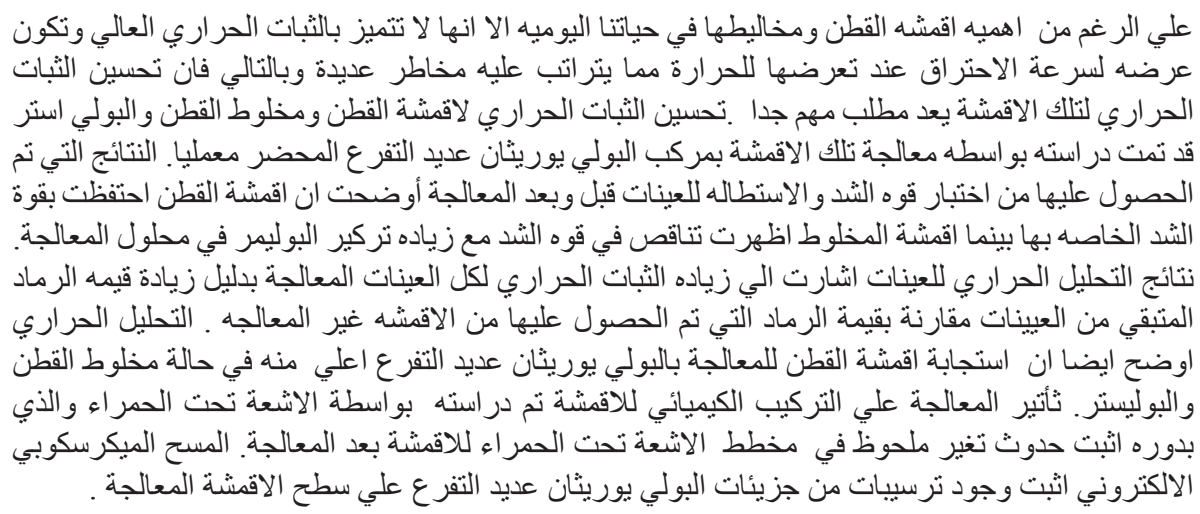

